\title{
After the MDGs: Citizen Deliberation and the Post-2015 Development Framework
}

\author{
Scott Wisor*
}

F

or those concerned with and affected by global development and human deprivation 2015 looms large, for this is the date by which the ambitious Millennium Development Goals (MDGs), the world's biggest promise, are to be achieved. As such, it will be a time to evaluate the successes and failures in meeting the various specific targets articulated by the MDGs, and a time to evaluate the adequacy and efficacy of the MDG framework itself. Perhaps more important, it will be the time to establish a new global framework to address the world's most pressing development problems. Indeed, some advocates, academics, and development practitioners have already turned their attention to designing such a potential successor agreement. ${ }^{1}$

Thus far, recommendations for a post-2015 development framework have focused largely, though not entirely, on the substance of a future agreement. However, the procedure for developing a successor to the MDGs deserves at least as much, if not more, attention. In this article I will: (1) review the history and impact of the MDGs; (2) identify several substantive flaws in the MDGs; (3) show that these shortcomings were in part a result of the procedure by which the MDGs were developed; and (4) recommend a new procedure that should be used to craft the post-2015 development framework. Specifically, it

\footnotetext{
${ }^{\star}$ I am grateful to a range of individuals for comments, discussions, and critical thoughts on the general idea of citizen deliberation about the post-2015 framework. Archie Law, Marc Chenery, Thomas Pogge, Christian Barry, John Dryzek, Alison Jaggar, Robert Chambers, Paul Ladd, Simon Burrall, Mukesh Kapila, Amy Pollard, Claire Melamed, an audience at Australian National University, a workshop on engaging poor people in the post-2015 period hosted by CAFOD, and many others have provided insightful comments and thoughts on the ideas in this article. I am also grateful to John Tessitore, Zornitsa Stoyanova, and Zach Dorfman for excellent editorial support. All mistakes remain my own. I first considered the idea of citizen deliberation for the post-2015 framework in Measuring Global Poverty: Toward a Pro-Poor Approach (Basingstoke, U.K.: Palgrave Macmillan, 2012), chapter 10.
}

Ethics \& International Affairs, 26, no. 1 (2012), pp. 113-133.

(C) 2012 Carnegie Council for Ethics in International Affairs

doi:10.1017/So892679412000093 
should be the role of advocates and allies of poor people to secure mechanisms for citizens, especially those most marginalized and oppressed, to participate meaningfully in the formation of (and subsequent adherence to) any future global development agreement. As I will show below, citizen assemblies offer one promising mechanism for putting poor men and women at the heart of discussions about global development priorities, and can potentially act as an accountability mechanism to increase the likelihood that any final intergovernmental agreement is responsive to the world's most deprived individuals. Citizen assemblies should complement planned or existing processes of intergovernmental deliberation.

\section{The MDGs: Procedure And Impact}

The Millennium Development Goals are an impressive achievement. The goals make concrete the commitments of the Millennium Declaration, agreed to by 189 members of the United Nations and adopted in 2000 by the General Assembly. The Millennium Declaration affirmed "certain fundamental values to be essential to international relations in the twenty-first century," including freedom, equality, solidarity, tolerance, respect for nature, and shared responsibility, in addition to calling for an end to war. The declaration included a number of quantitative development targets that would eventually be incorporated into the Millennium Development Goals (formally articulated in 2001), which were to be met by $2015 .^{2}$

A proper understanding of the development of the MDGs requires both a longterm and a short-term perspective. On the long view, the MDGs are best understood as the latest, and most widely endorsed, of a range of development targets set by the international community both within and outside the UN framework. Since at least the 1960s, various global goals and targets have been agreed to by states and international institutions. For example, in 1966 the United Nations set the goal of eradicating smallpox, which was achieved by $1977 .{ }^{3}$ At a series of conferences in the 1990s, a number of targets were set on various pressing issues, including poverty reduction, children's rights, women's rights, and reproductive health. ${ }^{4}$ Based on these world summits, in 1996 the Development Assistance Committee of the Organisation for Economic Co-operation and Development (OECD/DAC) formulated the International Development Goals, which were in many ways the predecessor to the MDGs. None of these previous agreements, however, had the impact or endurance of the MDGs. 
Over the shorter period of 1999 to 2001, the Millennium Declaration was crafted largely by John Ruggie, a professor of international relations and at the time a special adviser to Secretary-General Kofi Annan. The declaration is a sweeping document, a robust call for global and social justice, and a fundamental commitment to peaceful, sustainable development in the twenty-first century. But it also included development targets that were drawn almost entirely from the OECD/DAC's 1996 list. Following the adoption of the Millennium Declaration, Jan Vandemoortele and Michael Doyle (both at the time high-level members of the UN Secretariat) convened a group of experts, including staff from the United Nations, World Bank, International Monetary Fund, and OECD/DAC, to set global development goals based on the Millennium Declaration. This expert group designed the MDGs, selecting key goals, targets, indicators, and the baseline year for assessing progress. Once the MDGs were formulated, they then had to be "released" into the UN system. In a report from the secretary-general to the General Assembly, the MDGs were added on as an annex. The architects of the MDGs argued that acceptance of the report by the General Assembly, in combination with endorsement of the Millennium Declaration, signified assent to the MDGs, even though they were not explicitly mentioned by name. At the time, the U.S. administration argued that the member states of the United Nations, including the United States, never formally endorsed the MDGs with its full complement of targets, indicators, and commitments for action. ${ }^{5}$ The MDGs also received a lukewarm response from civil society organizations, which were concerned about "how the goals would fit with national ownership of development priorities, the reductionist nature of the targets (and the incentives and behaviours that this would create), the overriding focus on social and human development at the expense of economic aspects related to employment and infrastructure, the focus on the symptoms of poverty rather than underlying causes, and the much weaker structure of MDG 8, which sets out what the global community is expected to do to contribute to the goals." 6

From this rather quiet and inauspicious start, however, emerged an important and widely endorsed global development framework. Over time, national governments, international institutions, and civil society organizations began to use and promote the MDGs, making them the primary organizing mechanism for global development. Thus, the MDGs came to be seen as not merely the latest version of rhetorical grandstanding from the world's leaders but as different "from all other global promises for poverty reduction in their comprehensive nature and 
the systematic efforts taken to finance, implement and monitor them." A careful accounting of the Millennium Development Goals' impact to date is not yet complete, and further research is needed into how the goals have positively and negatively influenced efforts at promoting human development. Of course, the relevant counterfactuals - what would have happened had we not had the MDGs, and, alternatively, what would have happened if we had a different set of MDGs-cannot be known. Nonetheless, some tentative inferences can now be made based on a careful examination of the historical record since the goals were adopted in 2001, a review of the scholarly literature, and the self-reporting of development practitioners.

\section{The Substantive Critique of the MDGs}

It is largely agreed that the MDGs have produced significant benefits. They help to coordinate development objectives among a wide range of actors, emphasize some important neglected aspects of deprivation, are useful advocacy tools, maintain the political will for foreign aid and development policy more generally, and, most important, can be seen "as a significant step in the emergence of an international social norm that sees extreme poverty as being morally unacceptable in an affluent world." ${ }^{\prime \prime}$ It is difficult to demonstrate the overall effects of the MDGs, but we can infer their impact from several sources. During the period 2000 to 2009, official development assistance increased from $\$ 72$ billion to $\$ 128$ billion, with increasing flows to low-income countries and sub-Saharan Africa, reversing declines that occurred during the 1990s. ${ }^{9}$ Social sector spending increased, while investments in economic activity or infrastructure did not. ${ }^{10}$ Furthermore, during this period references in English-language books to the MDGs grew exponentially, even outpacing references to the UN's popular Human Development Index; twenty-five of thirty surveyed developing countries adopted the MDG framework; and nearly every international development report referenced the MDGs. ${ }^{11}$ The MDGs have also increased demand for more and better data on human deprivations, resulting in increased (though still lagging) statistical capacity in developing countries to monitor multidimensional economic and social development. ${ }^{12}$

Despite their strengths, however, there are a number of serious weaknesses in the MDGs, and their substantive shortcomings can be understood as failures of conception, framework, and content. At the conceptual level, the MDGs have employed a lowest-common-denominator approach largely focused on meeting 
minimal basic human needs, and have therefore moved away from the more robust and explicitly normative conception of human rights and social and global justice present in the Millennium Declaration. The framework of the MDGs was distorted and misapplied as it shifted from global development goals (at the time of agreement) to measurement and reporting at the national level, without ever specifying which political actors are responsible and without including any accountability mechanisms. The content of the MDGs and Millennium Declaration was weakened to gain global acceptance and meet feasibility requirements, omitting key indicators of development and human progress. These failures of conception, framework, and content are summarized in the following list of flaws:

National-level assessment: Global development goals could be consistent with nationally appropriate standards of assessment in one of two ways: either global goals could be set, and then national-level targets established such that in aggregate they attain those goals; or national targets could be set, and then aggregated into a set of global commitments. The MDGs were originally designed as global goals, but were subsequently assessed at the national level. This had the effect of making hard-to-reach but feasible (in the aggregate) targets, such as the halving of poverty, unattainable for the most deprived countries. Consequently, these countries appear as "failures" against the MDG yardstick even when making rapid progress on poverty reduction by historical standards. ${ }^{13}$

Millennium Declaration deflated: The Millennium Declaration was, among other things, a fundamental call for social and global justice, embracing core human values, framing development in the language of rights, calling for an end to war, placing environmental sustainability at the center of human development, and giving special attention to women and children-all within a framework of strengthened global governance. But the set of agreed goals that appeared in the MDGs lost much of the content of the Millennium Declaration. Gone, for example, was any target on the reduction of armed conflict or violence against women, though both are specifically mentioned in the declaration. While the MDGs may have kept the Millennium Declaration from being forgotten, they certainly did not preserve its spirit in whole. ${ }^{14}$

Rights: Though there have been efforts since the 1990s to integrate the human rights and human development frameworks, most notably through rights-based 
approaches to human development, the recognition of rights is absent in the MDGs. ${ }^{15}$

Inequality: The acknowledgment of inequality-both vertical, between the poorest and the wealthiest, and horizontal, between groups-is absent in the framing of the MDGs. ${ }^{16}$ The problematic absence of inequality is made more acute in the face of massive global and intrastate inequality. ${ }^{17}$ Tackling inequality should be central to development efforts as, assuming an unchanged rate of growth, inequality reduction by definition leads to poverty reduction. Furthermore, vertical and horizontal inequality is causally related to conflict, institutional corruption, economic mismanagement, and weaker social protection programs. ${ }^{18}$

Accountability: The MDG framework established no accountability mechanisms to hold states, international institutions, corporations, or civil society organizations responsible for their success or failure in achieving the MDGs. ${ }^{19}$

Misleading indicators: Some of the indicators selected for measuring achievement are misleading. For example, the World Bank's method of calculating the International Poverty Line (IPL), which is the most cited indicator for MDG 1 on eradicating extreme poverty and hunger, is not anchored in a meaningful conception of basic needs or capabilities, relies on purchasing power conversions that are sensitive to the prices and weights of all goods consumed in the economy rather than those goods that are predominantly consumed by poor people, ignores key dimensions of poverty, and takes the household rather than the individual as the unit of analysis. ${ }^{20}$

Missing dimensions: There are a number of fundamentally important issues that are absent from the MDGs. I concur with those who argue that the most important missing goal is that of freedom from violence. ${ }^{21}$ The absence is striking, as it is arguably the largest obstacle to human development, and the entire second section of the Millennium Declaration is devoted to peace, security, and disarmament.

Insensitivity to local context: The MDGs are largely insensitive to local context, as manifested in four distinct problems: understated targets (the targets are too easy to attain or already attained), overstated targets (where the speed of deprivation reduction required to meet the target could not possibly have been achieved), the inclusion of dimensions that are not relevant for some countries (or exclusion of dimensions that are relevant for some countries), and the insensitivity to domestic priorities and preferences.

Gender: Although the United Nations and many development agencies at least nominally recognize that gender is central to meeting all of the MDGs, and gender 
appears explicitly in MDGs 3 and 5, the overall integration of gender into the MDGs is inadequate. MDG 3 seeks to promote gender equality and empower women, but includes only a single target of eliminating gender disparity in education and only three indicators of gender disparity: in primary enrollment, the proportion of wage labor by women, and the proportion of seats in parliament held by women. MDG 5 focuses on reducing maternal mortality and, since 2005, access to reproductive health, but this again is a narrow spectrum through which to evaluate gender equity, omitting such potentially key indicators as time use (reflecting differential burdens for care work and household work), rates of physical and sexual violence, political influence, or access to and control of assets. $^{22}$

\section{The Procedural Critique}

The very procedure for setting the Millennium Development Goals was flawed in several ways. Many of the substantive flaws discussed above can be explained at least in part by these procedural shortcomings, including the lack of a deliberative process and the lack of inclusion of diverse participants. For example, the striking absence of gender in many of the development targets may be partially explained through the absence of civil society, and women's groups in particular, in the project of target setting. The lack of rigorous indicators for the commitment of wealthy countries to development can be explained by the fact that the goals were largely negotiated by wealthy country representatives. The lack of sufficient sensitivity to country context and the application of global goals to individual states may have also resulted in part from the exclusion of people from poorer countries in the process. Furthermore, because the goals, targets, and indicators were not developed in a transparent process, and there was no period of comment by the broader public, many of the flaws of the MDGs could not be corrected before the goals were released. I focus here on the period 1999 to 2001, rather than the longer time frame of the 1990s, during which various development targets were set and the OECD/DAC established the International Development Goals, for by reflecting on this shorter period we can begin to derive a more suitable procedure for the period 2012 to 2015 .

First, there was no transparency in the process by which the goals, indicators, targets, and baseline year were set. Certainly, the absence of transparency is not evidence of wrongdoing on the part of the MDG architects, but rather a reflection 
of the political circumstances at the time. The architects sought to find a mechanism by which to keep the ideas of the Millennium Declaration alive, but they had limited political support for doing so.

Second, there was no opportunity for feedback regarding the selected goals, targets, indicators, and baseline year. Had avenues for feedback been available, it is less likely (though still possible) that many of the substantive flaws would have persisted. At the very least, transparency and feedback would have provided the opportunity for transformative criticism.

Third, the process of selecting goals, targets, and indicators was not, as far as can be gleaned from the history as written thus far, particularly deliberative. ${ }^{23}$ Deliberative decision-making requires giving reasons to others, allowing one's own reasons and views to be subjected to scrutiny by deliberants, listening to the views of others and possibly revising one's own, and ultimately reaching a decision that is justified through that deliberative process. ${ }^{24}$ Because the architects of the MDGs were largely seen as rescuing the Millennium Declaration through a rearrangement of the document into quantifiable goals and targets, their task was seen as one of applying expertise rather than of public justification.

However, even if formal deliberation occurs, it should be noted that not all deliberative procedures are inclusive. For example, the Communist Party of China may deliberate regarding a particular five-year plan-providing reasons to other members of the party elite to pursue one policy over another, and considering the justificatory reasons given by others. But such deliberation does not entail that deliberants be representative of all those affected by the plan, nor will that deliberation pay particular attention to those people who are or are most likely to be marginalized, disadvantaged, or excluded. The MDGs were developed in a similarly exclusive manner, allowing only a few key civil servants and development experts to be involved in the process. $^{25}$

Some of these procedural flaws were in part a reflection of the constrained political environment in which the MDGs were formed. At the time, there was not a strong political constituency for a global development framework with measurable targets and indicators. There was also considerable hesitation among many countries, including the United States, for such an agreement. The MDGs were snuck in the back door at the United Nations, allowing their architects to sidestep normal discussion and voting. This may have been advantageous at the time-a procedural maneuver to gain formal political legitimacy for the goals when they may not have succeeded in an up-or-down vote. The process will be different 
in 2015, with public discussions regarding successor agreements already under way. $^{26}$

\section{Better Procedures: Citizen Participation and Deliberation}

Outside the context of the MDGs, Amartya Sen argues that in social evaluation we must recognize

the possible importance of public reasoning as a way of extending the reach and reliability of valuations and making them more robust. The necessity of scrutiny and critical assessment is not just a demand for self-centred evaluation by secluded individuals, but a pointer to the fruitfulness of public discussion and of interactive public reasoning: social evaluations may be starved of useful information and good arguments if they are entirely based on separated and sequestered cogitation. Public discussion and deliberation can lead to a better understanding of the role, reach, and significance of particular functionings and their combinations. ${ }^{27}$

The MDGs should be seen as one unique global exercise of social valuation. Setting up some global problems (and not others) as priorities for global action is an inherently evaluative exercise that commits discrete political actors, and thus their constituents, to take action. This act of social valuation, especially given its public and global nature, thus lends itself to global public reasoning.

"Beyond 2015 " is the umbrella organization currently coordinating civil society engagement on the post-MDG framework. They have, in my view, correctly called for the process of establishing the post-2015 framework to be open and inclusive (especially of the global South) and to be led by the United Nations. ${ }^{28}$ The United Nations has taken up this call and it is likely that a high-level panel will be nominated to lead this consultative process, beginning in 2012. The secretary-general's report to the General Assembly on the MDGs in June 2011 raised the issue of a post-2015 framework, and argued that

the post-2015 development framework is likely to have the best development impact if it emerges from an inclusive, open, and transparent process with multi-stakeholder participation. Using established global, regional, and national mechanisms and processes is one way to ensure that such deliberations benefit from the wide range of lessons learned and the experiences of different stakeholders. ${ }^{29}$

While this initial commitment is welcome, under the umbrella of inclusive multistakeholder participation falls a wide range of methods and activities that vary 
greatly in the degree to which they foster genuine deliberation and respect the capacity of citizens not just to provide information but to assess key issues. ${ }^{30}$

Participatory exercises may be categorized as extractive or deliberative. Extractive forms of participation seek the views of participants, frequently poor men and women, on a preselected research question; and extractive exercises, as opposed to deliberative exercises, can be an important source of information and the right tool for certain purposes. ${ }^{31}$ But in extractive exercises the selection and framing of the research questions and the work of analysis and conclusion remain in the hands of the social scientists and development practitioners. The United Nations may go the extractive route: a large survey or multiple consultations with poor men and women might satisfy civil society demands for engagement with the poor, and could be easily undertaken in the next few years.

Deliberative forms of participation, on the other hand, shift the focus from merely eliciting the existing views and preferences of informants to critical reflection and discussion by and among participants who have authority over the final decisions. This deliberation calls on participants not just to speak but to listen, reflect, learn, educate, collaborate, disagree, and then ultimately decide upon a final agreement or set of recommendations. The essence of deliberation is to seek reasons that can be justified to others engaged in the discourse. Deliberation also provides the opportunities for participants to engage in the difficult but necessary processes of making group-based decisions that often require compromise. Intersubjective conclusions or recommendations are thus the result of a process of social or public reasoning rather than an expression of the views of any particular group of analysts or policy-makers. Deliberation treats participants not as passive informants but as active agents.

Given the above, there are at least five reasons for using participatory citizen deliberation to develop a pro-poor post-2015 development framework:

Epistemology: Government representatives and the staff of international institutions do not always know what the priorities are or should be for the people who are the intended targets of any global development framework, but the poor men and women who live with these deprivations do. For example, freedom from violence is unlikely to be excluded from a recommended set of development goals by those who are subject to violence, as many of the global poor are.

Politics: Government representatives and officials of international institutions often fail to deliver progressive political outcomes. Official representatives may 
be driven by strict self-interest and undermine multilateral support for progressive change, or they may be constrained by domestic special interests that block their ability to secure pro-poor international agreements. For example, the lobbying of domestic pharmaceutical companies may constrain the ability of elected representatives to pursue pro-poor rules regarding patents for lifesaving medicines. Similarly, bureaucrats at international and regional institutions may face political and professional constraints on their ability to act.

Citizen deliberation can help to counteract the pressures placed on international agreements. Just as political pressure brought by special interests may undermine pro-poor change, political pressure created by citizen deliberation may help to promote pro-poor change. Furthermore, citizen deliberation can help to create political pressure needed to bring about compromise from official representatives. If citizens from diverse backgrounds reach agreement on a contentious issue, official representatives will be properly subject to public criticism should they fail to do the same.

Legitimacy: Development frameworks secured by governments, elite advocacy organizations, and development experts may lack legitimacy, particularly if all affected people are not represented in negotiating the frameworks. Legitimacy comes in degrees. In the domestic arena, political legitimacy may derive from the consent of the governed (through the practice of representative democracy) or the function of the authority (such as its ability to protect and promote basic human rights). In the international arena, assessing the legitimacy of global governance institutions, procedures, and agreements is more difficult. There are two broad approaches. The state-centered approach evaluates the international legitimacy of institutions, agreements, and policies by the degree to which they are the product of fair interstate relations, usually requiring state consent. The person-centered approach makes individuals the moral unit of analysis, and assesses legitimacy according to the degree to which the institution, procedure, or agreement protects individual interests or rights. ${ }^{32}$ Both approaches can be used to evaluate the legitimacy of a global development framework.

The legitimacy of the post-2015 framework can be assessed according to the degree to which states (or other legitimate representatives) ultimately agree to it through fair procedures and the extent to which it represents the genuine interests and will of affected citizens. Because individuals are the best (though not sole) representatives of their own interests and preferences, a new global development framework will gain legitimacy in so far as it is produced through procedures that allow citizens to represent those interests and preferences directly. Given that a 
global development framework is of greatest importance for the world's most deprived, an agreement that gives greater weight to the voices and perspectives of the global poor will be more legitimate. A politically legitimate agreement may arise through an intergovernmental process, but moral legitimacy can only be conferred by the participation of the world's citizens, especially the most marginalized and deprived, in shaping that agreement.

Ownership: Similarly, participatory mechanisms that include the voices of poor men and women, and development frameworks that can be seen at least in part as a product of their deliberation, will give poor people and their allies more ownership over any final development framework. If the next global development framework is viewed as a product of elite negotiation, those individuals and institutions who were not part of the negotiation will be less likely to push for its implementation, and less likely to hold political institutions to account for ensuring its success.

Accountability: Citizen deliberation in advance of any intergovernmental agreement will serve as an accountability mechanism, ensuring that official representatives are responsive to their citizens during the process of agreeing to a new development framework. For example, if citizen assemblies are held and produce concrete recommendations on environmental sustainability, and this topic is then excluded from a draft post-2015 framework, active citizens and advocacy organizations can use those citizen-driven recommendations to hold elected leaders to account.

\section{Citizen Assemblies And the Post-2015 Development FramewORK}

How can citizens participate in the crafting of a global development framework in a manner that will be agreeable to international organizations or member states of the United Nations? Can we do any better than to call for greater participation by low- and middle-income governments in the creation of the post-2015 development framework?

Citizen assemblies offer one promising mechanism. Such assemblies bring together a group of citizens from a defined political unit to deliberate on a given topic and to produce concrete outputs, either in the form of specific recommendations or by voting on key questions. They have been used in a variety of contexts, from local to national, and have addressed a variety of topics, from 
participatory budgets to constitutional reform, serving a variety of purposes, from actually directing government policy and resource allocation to expressing the general will of the governed.

Citizen assemblies are well suited to developing a post-2015 development framework: there is a clear research question; there is tangible empirical information to share with participants; and the core concepts required for assessing the MDGs and any successor agreement can be grasped by almost all citizens. In fact, poor men and women have privileged epistemic access to the core deprivations whose reductions should be at the heart of any subsequent global development framework, and therefore are particularly well situated for this type of evaluation. There are a variety of objectives that could be achieved through citizen assemblies that address future development frameworks. Citizens may deliberate about principles and values that should inform future development frameworks; and they may deliberate about the specific content of the framework, including the goals, targets, and indicators.

As noted, citizen assemblies have been convened on numerous topics. For example, a citizens' parliament was held in Australia in 2009, bringing together 150 people to make recommendations on improving Australian democracy. One participant was drawn from each federal district, from an initial random invitation list of 8,000, and thus the eventual participants represented a diverse crosssection of Australians. After participants produced a final set of recommendations, some went on to become politically active in their local communities, encouraging further deliberation and citizen participation. ${ }^{33}$

The largest multinational deliberation to date is the World Wide Views deliberation on climate change. Coordinated by the Danish Board of Technology, World Wide Views carried out deliberative exercises on global warming in thirty-eight countries-all on the same day, September 26, 2009. The deliberation brought together groups of roughly 100 citizens per country for a single day, and participants both voted on key questions after deliberation and produced recommendations on issues that were too complex to be captured in a simple vote. A synthesis of these deliberations produced nine key recommendations ahead of the Copenhagen round of climate negotiations. World Wide Views will conduct a second multinational deliberation on biodiversity in 2012 .

For the post-2015 development framework, the sites and participants must be selected so as to best complement existing processes. If, as is likely, UN-led consultations will engage development practitioners, civil society organizations, and government representatives and bureaucrats, citizen assemblies should be 
designed so as to ensure the participation of the most marginalized populations while also ensuring a diversity of participants. While in principle citizen assemblies could be conducted in nearly any country (with a few exceptions), in practice it is likely that advocates and facilitators will only be able to arrange participation by a small subset of countries. This sampling should be diverse, in terms of geographic location, domestic political arrangements, religious orientation, as well as the key developmental challenges facing the individual countries.

Although citizen deliberation is one key avenue to ensure that the voices of the most marginalized and oppressed are heard, it is crucial that citizens of developed countries also be included in the deliberations. One of the major shortcomings of the MDGs was a lack of strong commitments from wealthy countries regarding their development policy. Wealthy citizens must therefore also reflect on the goals and commitments that should bind their governments. Just as an example, if citizen assemblies are conducted in, say, a dozen countries, we might expect one European, one North American, two Asian, one Pacific, two sub-Saharan African, two Latin American, one Eastern European, and two North African or Middle Eastern. These countries should include those with citizens living in conflict and postconflict, some with severe deprivations and some with very few, a broad range of religious beliefs and political backgrounds, varying levels of gender equity, a variety of political structures, and so on.

Within a country, the sampling of participants should again reflect a diversity of perspectives, but should be weighted toward ensuring that the most marginalized and excluded individuals are represented. On this view, participant selection need not focus exclusively on a proportional representation of citizens that reflects the country's demographic makeup. Rather, citizen selection for post-2015 assemblies should not be designed as a statistically representative sample, but should "stack the deck" for social justice and serve as a counterweight to existing political processes.

At the local level, one could imagine conducting assemblies at the level of the village or town, producing recommendations on development frameworks for the local community or national government, while also making recommendations for the post-2015 global development framework. At a higher level, nationally representative assemblies could be convened to deliberate on development goals. Such deliberation could again focus on either national or global development frameworks (or both). At a yet higher level, regional-level deliberation would be possible in which citizens could produce recommendations for new global development frameworks. Such regional negotiation would have the advantage 
of including more diverse perspectives in the conversation. Finally, global citizen assemblies could be convened. While a true global citizens deliberative assembly has not yet been held (that is, one drawing directly on citizens rather than through NGOs, such as was the case in Rio in 1992), there is no theoretical or practical reason why it could not happen; and it is possible that in the years preceding 2015, global deliberation by unelected citizens will have occurred on other issues. A successfully designed global deliberative assembly would draw participants from previously held regional or local citizen assemblies, as these participants would have experience with the deliberative process and background knowledge of the key issues.

Citizen assemblies need not eschew the important role of expertise in making good public policy. Such assemblies on climate change, for example, should have access to scientists who can provide information on the latest and best thinking on the ecological impact of current and future levels of carbon output, economists who can provide information on the economic impact of various proposals to curb climate change and create climate adaptation financing, political scientists who can provide information on the governance mechanisms available for enforcing a climate agreement, and so on. In previous citizen assemblies, experts have been called on to present their views and answer questions. Similarly, a citizen assembly for the MDGs could take testimony from those who originally developed the MDGs, academics who have criticized or suggested revisions to the existing approach, statisticians who could provide guidance on the possibilities of data collection, and advocates from civil society and UN agencies (for example, UNICEF, the UN Development Progamme, and the World Health Organization) who could provide critical commentary based on personal experience working in development under the framework of the MDGs.

To be clear, citizen assemblies should be designed to complement rather than entirely replace other forms of deliberation and decision-making. Identifying the best method for choosing indicators of food security or maternal mortality, for example, will certainly require input from technical experts in addition to the participation of citizens. Such assemblies must be seen not as the final arbiters of the best post-2015 development framework, but rather as an indispensible part of a broader deliberative system that can deliver a politically and morally legitimate pro-poor development framework for the future.

Finally, a global deliberative process that prioritizes citizen participation might have a series of additional benefits. It could demonstrate the advantages of global 
citizen deliberation, increasing support for a more permanent global citizen assembly. ${ }^{34}$ If citizen assemblies are included within the official UN post-2015 process, it would also challenge the widely held belief that multilateral and international institutions are incapable of permitting democratic influence and are hostile to democratic participation.

\section{Challenges in Real-World Deliberation}

There are a number of challenges for advocates of citizen participation regarding the post-2015 framework, and in this section I raise some of these issues and provide possible responses to them.

All deliberation inevitably reflects perceived or actual power inequalities among participants, and between organizers and participants. For example, men of a certain social and economic class may be more accustomed to speaking and being heard in some contexts than men from lower socioeconomic groups, or than their female counterparts. More educated participants may be more likely to dominate deliberation than their less educated counterparts. However, the fact that power inequalities inevitably influence deliberative outcomes is not an argument against deliberation, but an argument in favor of taking steps to mitigate the harmful effects of power inequalities. Procedural constraints can be put in place to ensure that all participants have equal opportunity to deliberate-for example, by facilitators guaranteeing that each participant has equal allotted speaking time and that there is a mechanism in place for sanctioning those who engage in harmful or threatening speech. Additionally, safe spaces can be created where marginalized or disadvantaged groups may deliberate before returning to a larger forum (for example, at local assemblies in societies characterized by very high levels of gender inequality, all-female deliberations could be conducted as one component of the larger deliberations ${ }^{35}$ ). Facilitators should also provide participants a forum to individually dissent from the broader group consensus-by, for example, video testimonial or written complaints.

Even in the absence of significant power inequalities, diversity in general will present challenges for citizen assemblies. Linguistic diversity in many countries, and in a global forum, will require skilled translators to share information. Given the diversity of the circumstances of participants, it may be necessary to provide additional support to some-for example, to provide clothing, shelter, and opportunities for sanitation that will allow participants to be respected by 
their peers. Psychological support may also be necessary; and the difficulties in including some participants in deliberations, such as child laborers or victims of sex trafficking, may require that these groups be represented by their advocates.

Some participants will not be literate, and this will constrain the kinds of information sharing and collection that can occur. However, there is no reason that this cannot be overcome through other methods of communication and information collection. Participatory research regularly engages illiterate participants, and their lack of literacy is no insurmountable obstacle to full participation. Furthermore, asking a poor person to leave her home and work for some extended period of deliberation raises distinct practical and ethical challenges. In addition to financially compensating participants for their time, it is necessary for organizers to ensure that each participant and her family are not disadvantaged in the near or long term as a result of her absence. Importantly, participants must be given the opportunity to speak freely with certainty of confidentiality before any final agreement is reached. For example, if a participant raises issues of corruption, or access to justice, or violence from men during the deliberative process, her identity must be concealed so that she does not face reprisals from a violent husband, a corrupt government, or a broken judicial system. Protection of participants must guide each step of the process.

The MDGs may be entirely unfamiliar to participants in poor countries, many of whom lack access to information and news, in addition to formal education. But this is no different than in developed countries, where a scant minority of citizens are familiar with the MDGs. In any case, development frameworks are not so complex that participants cannot become familiar with them in a relatively short period of time. No previous knowledge of development frameworks is needed to critically reflect on the MDGs and any successor agreement. Participants must be provided information and education along the way.

Perhaps the biggest challenge facing citizen assemblies is securing political uptake for them. Thus far I have argued that citizen deliberation is needed to complement other forms of consultation and deliberation that will fall within the UN process. If this is correct, and states, civil society, development agencies, and international institutions should also be a part of the post-2015 process, why would governments and international institutions accept the input of citizens? First, because constituents and advocates exert public pressure on elected representatives. The effect of organizing and campaigning should not be understated, given that the many target-setting world summits of the 1990s, commitments on debt relief, pledges regarding foreign assistance, and even early 
commitments on the post-2015 process are all the result of effective campaigning. Second, because it will produce good policy-that is, citizen input will produce useful insights that will improve the next framework. Third, because it may provide political cover for desired compromise in the face of political obstacles. After all, many government representatives do desire pro-poor global governance, but they must be able to point to political support for any controversial positions they may seek to take. And, finally, because it can help combat the view that global governance institutions are hostile to democratic participation. As the United Nations and other multilateral organizations seek to secure support and prove legitimacy in the face of growing crises that inevitably require global action (for example, issues of food, climate, and finance), their openness to democratic public participation may strengthen their position in the face of a world that is sometimes hostile to multilateralism.

\section{Conclusion}

It is commonplace for the development community to proclaim a desire to hear the voices of poor people, and countless exercises have indeed been undertaken to share these voices with development professionals. But rather than providing a forum for merely making statements, it would be far better to provide one for people to deliberate in-to speak, be heard, listen, reflect, negotiate, analyze, and decide. Advocates should not simply try to input the views of the deprived and marginalized into preexisting political processes and prefabricated development narratives. Rather, they should create deliberative spaces where citizens, as figures of authority, actively seek to address critical global challenges and influence the policy-makers who will ultimately determine the post-2015 agreement. Complementing extensive consultative processes and transparent feedback with citizen deliberation would be a critical step in moving toward a pro-poor development framework in 2015, and toward more democratic and inclusive global governance in general. Furthermore, demonstrating the feasibility and power of deliberation on a global scale over global issues would enhance the possibility of deliberative mechanisms being employed in global governance in the future.

\section{NOTES}

1 Though others have argued that focusing now on the post-2015 framework will draw attention away from achieving the MDGs, there is no reason that the development community cannot both maintain support for efforts to meet the existing MDGs and give considerable attention to the next global development framework. The human and financial resources needed to develop a pro-poor 
post-2015 development framework are minuscule in comparison to the resources currently devoted to meeting the MDGs.

${ }^{2}$ Although the goals were agreed to in 2001, the period for assessing progress in achieving the goals was backdated to 1990 .

${ }^{3}$ Richard Jolly, “The MDGs in Historical Perspective," IDS Bulletin 41, no. 1 (2010), pp. 48-50.

${ }^{4}$ For a full list, see United Nations Department of Economic and Social Affairs, The United Nations Development Agenda: Development for All (New York: United Nations, 2007).

${ }^{5}$ Jan Vandemoortele, “The MDG Story: Intention Denied," Development and Change 42, no. 1 (2011), p. 6. In 2005 , U.S. ambassador to the UN John Bolton attempted to eliminate any references to the MDGs in Summit Outcome documents, but after widespread global condemnation, the MDGs were affirmed by President Bush in his speech to the General Assembly in September 2005. Bolton's reluctance must be understood in light of two factors: a strong opposition to the UN and multilateralism in general, and a strong opposition to any obligations that might be incurred by the United States from an endorsement of the MDG framework.

${ }^{6}$ Claire Melamed and Andy Sumner, “A Post-2015 Development Framework: Why, What, Who?” Paper prepared for the ODI/UNDP Cairo workshop on a post-2015 Global Development Agreement, October 26-27, 2011 (London: Overseas Development Institute); http://www.odi.org.uk/resources/docs/7369. pdf, p. 4 .

7 David Hulme, “The Millennium Development Goals: A Short History of a Big Promise," BWPI Working Paper 100, Manchester, Brooks World Poverty Institute, 2009, p. 4. The Millennium Declaration and MDGs "represented a hard-won consensus on how to tackle a range of difficult issues confronting the world, not least in the matter of how to promote sustainable development for the world's poor. Within the Declaration, the agreement on a few measurable targets for achievement, in most cases by 2015 , was a notable step, and their translation into a structured framework of Goals, Targets and Indicators created a distinctive approach to encouraging development and international support for it." Richard Manning, Using Indicators to Encourage Development: Lessons from the Millennium Development Goals, DIIS Report 2009:01 (Copenhagen: Danish Institute for International Studies, 2009), p. 5.

${ }^{8}$ David Hulme and James Scott, "The Political Economy of the MDGs: Retrospect and Prospect for the 'World's Biggest Promise," New Political Economy 15, no. 2 (2010), p. 294.

9 Charles Kenny and Andy Sumner, "More Money or More Development: What Have the MDGs Achieved?” Center for Global Development Working Paper 278, p. 4.

${ }^{10}$ Ibid., pp. 4-5.

11 Ibid.

${ }^{12}$ Manning, Using Indicators, p. 38.

${ }^{13}$ Michael Clemens, Charles Kenny, and Todd Moss, "The Trouble with the MDGs: Confronting Expectations of Aid and Development Success," World Development 35, no. 5 (2007), pp. 735-51; and William Easterly, "How the Millennium Development Goals Are Unfair to Africa," World Development 37, no. 1 (2009), pp. 26-35.

${ }^{14}$ Ashwani Saith, "From Universal Values to Millennium Development Goals: Lost in Translation," Development and Change 37, no. 6 (2006), pp. 1167-99; Naila Kabeer, "Can the MDGs Provide a Pathway to Social Justice?" Institute of Development Studies, 2010; Phil Vernon and Deborrah Baksh, "Working with the Grain to Change the Grain: Moving Beyond the Millennium Development Goals," London, International Alert, 2010; and Manning, Using Indicators.

15 Philip Alston, "Ships Passing in the Night: The Current State of the Human Rights and Development Debate Seen Through the Lens of the Millennium Development Goals," Human Rights Quarterly 27, no. 3 (2005), pp. 755-829.

${ }^{16}$ Sakiko Fukuda-Parr, "Reducing Inequality-The Missing MDG: A Content Review of PRSPs and Bilateral Donor Policy Statements," IDS Bulletin 41, no. 1 (2010), pp. 26-35.

17 The top decile of income earners have 57 percent of global income, and the bottom decile of income earners had 0.6 percent of global income. The bonuses of Goldman Sachs in 2009 equaled the total income of the 240 million poorest individuals. Branko Milanovic, "Global Income Inequality," INET, 2010; siteresources.worldbank.org/INTDECINEQ/Resources/inet.pdf.

${ }^{18}$ See, for example, Frances Stewart, ed. Horizontal Inequalities and Conflict: Understanding Group Violence in Multiethnic Societies (Basingstoke: Palgrave, 2008) and United Nations Research Institute for Social Development, Combating Poverty and Inequality: Structural Change, Social Policy, and Politics (Geneva: UNRSID, 2010).

19 In practice, low- and middle-income countries are subject to a number of evaluative exercises, but even these exercises lack any enforcement mechanism or even a procedure for addressing a lack of progress. The lack of accountability is particularly acute in the case of the developed countries, who are the primary duty bearers of MDG 8 . 
${ }^{20}$ On a related note, some targets for deprivation reduction have been diluted. The primary target of the first and most prominent Millennium Development Goal, to eradicate extreme poverty and hunger, is to halve the proportion of people in the world living on less than \$1.25 per day. This indicator represents a set of goalposts clearly moved. The original international goal on poverty reduction set at the Rome Declaration in 1996 was to halve the absolute number of undernourished people by 2015. This goal was weakened first in the Millennium Declaration and then in the MDGs by shifting the hunger and target reductions to track the proportion of poor people in the developing world rather than the absolute number of people in the entire world. This has had the impact of raising by about half a billion the number of people that would still be poor if the MDGs were met by 2015. See Thomas W. Pogge, Politics As Usual: What Lies Behind the Pro-Poor Rhetoric (Cambridge: Polity Press, 2010).

${ }^{21}$ Vernon and Baksh, "Working with the Grain."

22 "This explicit inclusion in just two MDGs is too narrow, and sidelines other gender-specific risks and vulnerabilities, roles and responsibilities, and power relations. It is unlikely to lead to gender equality and the empowerment of girls and women, or tackle the development challenges that must be overcome for sustainable poverty reduction. These limitations are compounded by the gender blindness of other MDG indicators, and the fact that the gender dynamics that cut across the goals are relatively invisible in policy dialogues." Nicola Jones, Rebecca Holmes, and Jessica Espey, "Gender and the MDGs" Briefing Paper 42, September (London: Overseas Development Institute, 2008).

${ }^{23}$ Hulme and Scott, "The Political Economy of the MDGs," pp. 293-306.

${ }^{24}$ See, among others, Amy Gutmann and Dennis Thompson, Why Deliberative Democracy? (Princeton, N.J.: Princeton University Press, 2004).

25 Again, this is for the period 1999 to 2001 . The longer-term process of international target setting was more participative. See Fukuda-Parr, "Reducing Inequality."

26 The contemporary political environment offers both opportunities and risks for securing a post-2015 framework. Favorably, most countries have now accepted the MDGs as a critical component of global development work, most influential donors work from and toward the MDGs, and most (though not all) civil society organizations have come to seriously support the MDGs. For example, in a survey of global civil society activists from the South, 87 percent of respondents supported an overarching global development framework to follow the MDGs. See Amy Pollard et al., "10o Voices: Southern NGO Perspectives on the Millennium Development Goals and Beyond," IDS Bulletin 42, no. 5 (2011), pp. 120-23. However, there are considerable challenges reverberating through the international system that may make securing agreement on a post-2015 framework more difficult. On the one hand, following the global financial crisis of 2007-2009 and the continuing Eurozone crisis (whose final resolution is still unknown at the time of writing), governments may be less willing to agree to any framework that may require additional resources for development. On the other hand, the presence or threat of existing crises-e.g., climate, goods, finance, resource scarcity, and so on-and the interrelated and transnational nature of these crises may strengthen the commitment of national governments to a meaningful and potentially binding global development framework. On the political environment today and in 2000 when the goals were agreed to, see Melamed and Sumner, "A Post-2015 Development Framework."

27 Amartya Sen, The Idea of Justice (Cambridge, Mass.: Harvard University Press, 2010), pp. 241-42.

${ }^{28}$ See http://www.beyond2015.org.

${ }^{29}$ United Nations General Assembly, Annual Report of the Secretary-General, "Accelerating Progress Towards the Millennium Development Goals: Options for Sustained and Inclusive Growth and Issues for Advancing the United Nations Development Agenda Beyond 2015," A/66/126, 2011, p. 15.

$3^{\circ}$ At the time of writing, the United Nations Development Programme is planning to undertake consultative efforts on behalf of the UN, but this is expected to be led largely by country-based UN offices and will not focus primarily on engagement with poor men and women. See Amy Pollard, "Post-MDG Update," CAFOD policy team blog, January 16, 2012; cafodpolicy.wordpress.com/2012/01/16/post-mdg-update/.

${ }^{31}$ My distinction here between extractive and deliberative participation draws heavily on Robert Chambers's work. See, among many other sources, Robert Chambers, Revolutions in Development Inquiry (London: Earthscan, 2008).

${ }^{32}$ Fabienne Peter, "Political Legitimacy," in Edward N. Zalta, ed., Stanford Encyclopedia of Philosophy (Summer 2010 ed.); plato.stanford.edu/archives/sum2010/entries/legitimacy/.

33 John Dryzek, “The Australian Citizens' Parliament: A World First," Journal of Public Deliberation 5, no. 1 (2009), pp. 1-7.

${ }^{34}$ For one proposal, see John Dryzek, Andre Bachtiger, and Karolina Milewicz, "Towards a Deliberative Global Citizens' Assembly," Global Policy 2, no. 1 (January 2011), pp. 33-42.

35 One might think that this suggestion is unnecessarily exclusionary. By separating men and women at some points in deliberation, we may be reinforcing rather than challenging existing gender inequalities. However, one has to consider the alternatives. Consider a society where women are either de jure or de 
facto excluded from holding political office, suffer high rates of violence, and are systematically vulnerable to men. We cannot assume that procedural constraints alone will automatically make men and women deliberating equals. Women may therefore benefit from a space of their own to deliberate and articulate their views. After this deliberation has happened, men's and women's views must be brought back together in a larger deliberation. The creation of a temporary safe space need not be seen as condoning gender inequality, but rather as a way to promote women's agency in contexts where it is too often denied. 